\title{
Benefits of Linked Data for Interoperability during Crisis Management
}

\author{
R. Roller ${ }^{\mathrm{a}}$, J. Roes ${ }^{\mathrm{a}}, \mathrm{E}$. Verbree ${ }^{\mathrm{b}}$ \\ a TNO, Connected Business Group, Kampweg 5, 3769 DE Soesterberg, Netherlands - jasper.roes@tno.nl \\ ${ }^{\mathrm{b}}$ TU Delft, Faculty of Architecture and the Built Environment, Julianalaan 134, 2628 BL Delft, Netherlands - e.verbree@ tudelft.nl
}

\section{Gi4DM and ISPRS, WG IV/7}

KEY WORDS: Linked Data, Ontology, Data sharing, Crisis management, Power cut, Flood, Smart grid, Utility domain

\begin{abstract}
:
Floodings represent a permanent risk to the Netherlands in general and to her power supply in particular. Data sharing is essential within this crisis scenario as a power cut affects a great variety of interdependant sectors. Currently used data sharing systems have been shown to hamper interoperability between stakeholders since they lack flexibility and there is no consensus in term definitions and interpretations. The study presented in this paper addresses these challenges by proposing a new data sharing solution based on Linked Data, a method of interlinking data points in a structured way on the web. A conceptual model for two data sharing parties in a flood-caused power cut crisis management scenario was developed to which relevant data were linked. The analysis revealed that the presented data sharing solution burderns its user with extra costs in the short run, but saves resources in the long run by overcoming interoperability problems of the legacy systems. The more stakeholders adopt Linked Data the stronger its benefits for data sharing will become.
\end{abstract}

\section{INTRODUCTION}

Floodings represent a permanent risk to the Netherlands in general and to her power supply in particular (Waterschappen, 2015). By damaging Electrical Assets increased water levels may cause a power cut that threatens various vital societal activities such as healthcare, schooling and transport (van Dongen et al., 2013). Due to these sector-interdependencies many different stakeholders are involved in crisis management, e.g. grid operators, water boards ${ }^{1}$ and safety regions ${ }^{2}$. They depend on each other's sector-specific information (van Dongen et al., 2013), making data sharing essential.

However, the implementation of data sharing meets problems of interoperability, since stakeholders use different ways to describe and maintain their information. Consequently, datasharing parties work together suboptimal leading to suboptimal decisions within crisis management.

At the moment, cross-sector data sharing systems are rare within crisis management in the Netherlands, since standards are mainly developed within one sector and cannot communicate with each other (Kalcheva, 2015; ACIR, 2005). Stakeholders mainly use traditional channels, like email, phone, or database merges to exchange information during a crisis (Book, Bastiaans \& Bruinenberg, 2014). This makes data sharing slow and error prone since no common conceptualization of the data exist between the stakeholders. Misunderstandings regarding the correct interpretation of the data often occur which are tediously solved on an individual basis.

This study is part of the CERISE-SG project $^{3}$ (CERISE, 2015). Its purpose is to create a novel data sharing solution that overcomes these interoperability issues between the stakeholders, and will therefore make crisis management more effective and efficient.

The study presented in this paper explores the suitability of Linked Data to tackle these challenges. Linked Data describes a method of interlinking data points and data concepts in a

\footnotetext{
${ }^{1}$ Regional water authorities in the Netherlands. Responsible for flood protection.

${ }^{2}$ Unions of Dutch municipalities coordinating crisis management.

3 Combining Energy and Geo information standards as enabler for Smart Grids that focuses on interoperability between the utility-, geo-, and government domain.
}

structured way on the web (Eckartz \& Folmer, 2014). The data can then be read automatically by computers which enables data from different sources to be connected and queried to derive information encoded in the interlinks. Data links will be structured according to a conceptual model that defines relevant data concepts and their interrelations.

The contribution of this study is the creation of a conceptual model for crisis management and provide evidence for its suitability to improve interoperability. Moreover, by successfully using Linked Data within cross-sector crisis management the usage boundaries of this technology will be extended.

Based on requirements of two datasharing parties (Alliander, the grid operator and HHNK, the water board of Holland's Noorderkwartier) a small, non-generic but clearly defined crisis scenario will be developed featuring primary effects of a flooding on the electricity grid. Relevant data concepts will then be selected, defined and interrelated within the conceptual model. Finally, this model as well as Linked Data in general will be assessed based on interoperability measures. Furthermore, the presented solution will acknowledge future developments within crisis management, which will become more distributed and less centrally controlled (Book, Bastiaans \& Bruinenberg, 2014). This entails that a greater variety of standards for data description and management will have to be harmonized but also that the need for privacy and security of sensitive data will increase. We argue here that Linked Data and our conceptual model meet the challenges of increasingly complex crisis management and provide a smart data sharing solution.

This paper includes six sections. Section 2 presents previous work. Section 3 describes the use case scenario. Section 4 explains the concept of Linked Data. Section 5 presents our conceptual model for data sharing and Section 6 includes an anlysis of it. Section 7 discusses the results of the study and future prospects. 


\section{PREVIOUS WORK}

Currently there is a large diversity of crisis management systems in place in the Netherlands. Traditional channels like email or phone are still used although they are time costly and error prone. For example, Alliander and HHNK currently exchange data via USB sticks (Book, Bastiaans \& Bruinenberg, 2014). Besides, IT systems such as Eagle One, MultiTeam, and LCMS 2.0 increase in usage (Fan \& Zlatanova, 2010; Esri, 2015). In case of a crisis, the safety region determines affected stakeholders and asks them to provide data on their area of responsibility. Stakeholders prepare their information locally in text plots or map format, which are then layered-up within the central crisis management system (van Dongen et al., 2013). The resulting mash-ups provide the same picture of the crisis to all stakeholders involved, who seem to better cooperate since they all have the same base for decision-making.

However, these systems do not take crisis-specific requirements for data sharing into account. First, by informing stakeholders only during the crisis about data needed, valuable time is lost (van Dongen, 2013). Each crisis requires different data from a stakeholder, who therefore has to do tedious preparatory work for each crisis. For example, in order to localize broken Pumping Stations during a power cut only requires data on electrical Pumping Stations whereas a flood requires data on both mechanical and electrical Pumping Stations.

Second, by preparing their data locally without accord, stakeholders run the risk of using sector-specific descriptions for their information. These might not be understood or misunderstood by stakeholders from other domains which decreases semantic interoperability. For instance, the HHNK uses the term "kunstwerken" when referring to infrastructural engineering constructions, such as bridges (de Landmeter \& van Giessel, 2015). A flood-management novice, however, would probably interpret this label to represent some "art work".

Third, since the course of a crisis is often unpredictable, data requirements and the constellation of involved stakeholders might suddenly change. This might lead to an overload of the central crisis management system as it has to integrate constantly changing datasets (Zlatanova et al., 2014).

Fourth, current systems access and display all the data available not differentiating between stakeholders' roles, which require different kinds of information (Zlatanova et al., 2014). This may create an information overload since the human cognitive processing capacity is limited (Endres et al., 2015). For instance, during a flood-caused power cut, the electrical grid operator only has to know the location of affected electricity users in order to re-ensure power supply. Buildings damaged by water alone that are still supplied with electricity are irrelevant for this stakeholder.

The current study addresses these issues with a novel data sharing solution based on Linked Data. Stakeholders specify the datasets they are willing to share, which are then interlinked in a structured way. This happens before the crisis, in order to fully focus on data sharing - not on preparation - during the crisis. Semantic interoperability will be enforced by linking the data to a conceptual model that provides formal definitions of data concepts and defines their interrelations. This model can then be linked to local models of the individual stakeholders to provide a mapping cipher for translating concept definitions from one domain to another. Finally, depending on the crisis situation and the stakeholders' information needs, the data can be specifically queried in order to retrieve relevant information.

${ }^{4}$ Landelijk crisis management system. All safety regions use this system for data sharing during crises.
To this point, Linked Data has only been sparsely used within crisis management in the Netherlands. The only case known to the authors is a sector-specific application within the firefighting domain. The firebrigade of Amsterdam-Amstelland would like to share their data about incidents and fire safety using Linked Open Data (van Leeuwen, 2015). Published Data will be linked to an open twitter account, the incident room, and firebrary, a conceptual model holding data about fire-fighting terms (Firebrary, 2015). The intention is to inform bypassers how to behave correctly during a fire-related crisis and also to encourage them to inform the firebrigade about new disasters (van Leeuwen, 2015).

This study aims to extend this work by applying Linked Data to cross-sector crisis situations and by assessing the suitability of a novel conceptual model for crisis management.

\section{THE CRISIS SCENARIO}

\subsection{Context and Scope}

Floodings put the energy network at risk, since Electrical Assets can break down if the water level exceeds a critical threshold, thus, increasing the probability for a power cut (Book, Bastiaans \& Bruinenberg, 2014). This will affect a great variety of electricity users like schools, hospitals, and electrical Pumping Stations, the main users of interest within this study. In case of a power cut they will stop running and therefore cannot combat the flooding by draining the crisis area (de Landmeter \& van Giessel, 2015). Moreover, just like Electrical Assets, these Pumping Stations are also directly vulnerable to high water levels.

The development of the crisis is described in Figure 1. As a result of a flooding, Electrical Asset 1 breaks down and therefore can no longer supply electricity to the users in its supply area. Thus, the affected electrical supply area of that flooded Electrical Asset and the electricity users within it have to be identified. Pumping Station 3 is located in the affected supply area and consequently breaks down. Now, countermeasures against the flooding have to be taken, for example by replacing the broken Pumping station with a functioning one, which involves a reconfiguration of the Pumping Station grid. Pumping Station 4 is located in a non-affected supply area. If it is close by, it can be used to drain the flooded area, otherwise, a battery or a generator can be used for temporary power supply. In the long run, the electricity grid has to be reconfigured in order to supply electricity to the most vulnerable users (e.g. hospitals, Pumping Stations). Once the water is gone, damaged Electrical Assets and Pumping Stations have to be repaired in order to be put back on the grid.

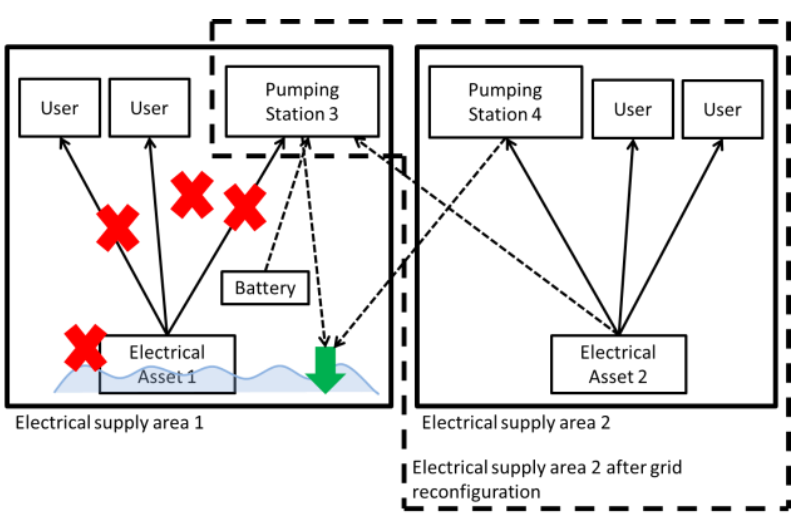

Figure 1. Concepts and processes within crisis scenario of flood-caused power cut 
The scope of data sharing during this crisis scenario is based on stakeholders' requirements as well as organisational constraints, such as the availability of time (Table 2 ). This provides a clearly defined, but also highly limited scenario which is proficient for this exploratory pilot study.

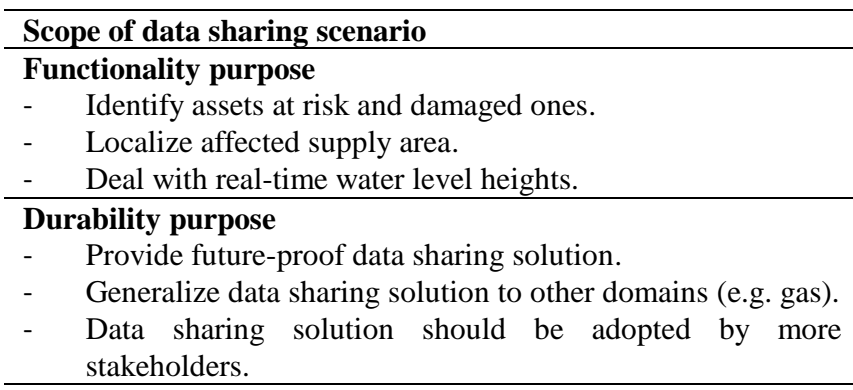

Small user community

Only Alliander and HHNK use data sharing solution. It is therefore easier to adjust it to the stakeholders' IT landscape than the other way round.

\section{Closed application environment}

Alliander and HHNK only share data with each other. No open data wanted.

\section{Economical purpose}

Data sharing solution should impose little extra costs on the stakeholders.

\begin{tabular}{|c|}
\hline $\begin{array}{l}\text { Limited time available } \\
-\quad \text { Data sharing process has not been running for a suffic } \\
\text { long period. } \\
\text { - } \quad \text { Implementation does not exist. } \\
\text { - } \quad \text { Assessment process must not be too time consuming. }\end{array}$ \\
\hline $\begin{array}{l}\text { User-centred development } \\
\text { Development of data sharing solution is done in close } \\
\text { cooperation with Alliander and HHNK and based on their } \\
\text { explicit requirements. }\end{array}$ \\
\hline
\end{tabular}

Table 2. Scope of data sharing scenario

\subsection{Stakeholders}

The two primary stakeholders in this study are Alliander, the electrical grid operator and manager of Electrical Assets and $H H N K$, the water board of Holland's Noorderkwartier, who manages the flood-protective assets. They exchange information about water levels and their respective Electrical Assets (e.g. power stations and Pumping Stations) in case of a flooding. With this information exchange they want to localize the affected assets and supply areas by a power cut, and reconfigure the power grid accordingly (Fig. 3). Their goals are to re-ensure power supply and reduce the effects of the flooding.

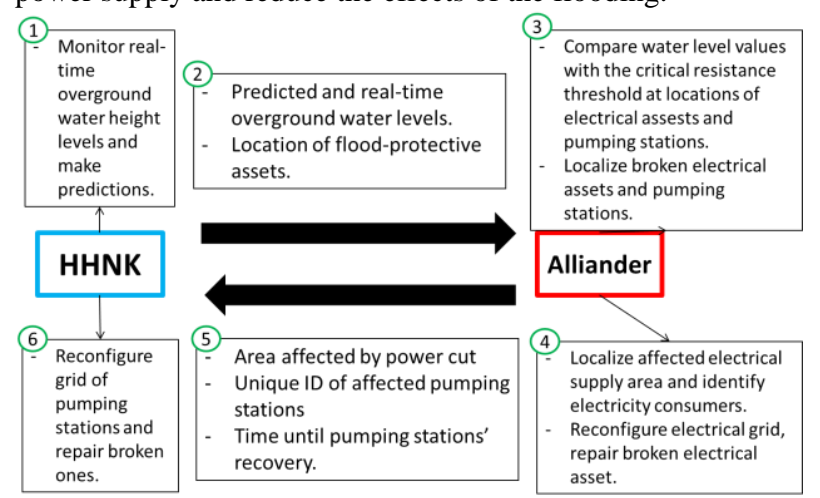

Figure 3: Information exchange between Alliander and HHNK during a flood-caused power cut
In addition, there are many secondary stakeholders who hold relevant data, prepare them for the main stakeholders and have other responsibilities within crisis management not directly related to flood control and electrical grid management. It is important to be aware of all stakeholders in order to get a full picture of crisis management. The following paragraphs give an overview of the parties, including a description of their role

\subsubsection{Primary stakeholders}

- Alliander: Largest network operator of the Netherlands distributing gas and electricity. Manages middle- and lowvoltage components of the grid. Shares data with the HHNK to improve crisis management.

HHNK: Hoogheemraadschap Hollands Noorderkwartier is one of the 25 Dutch water boards. Responsible for regions north of the North Rhine canal in the province of North Holland. Manages water ways as well as the sewage system, and maintains flood protection facilities.

\subsubsection{Secondary stakeholders}

- Hospitals: Take care of people that have injuries caused by the flooding and/or power cut.

- Kadaster: Netherlands' Cadastre, Land Registry and Mapping Agency collects and registers administrative and spatial data on property and the rights involved. Maintains the Key Registers Cadastre and Topography which include geo-data buildings locations and ground surface heights.

- KNMI: Koninklijk Nederlands Meteorologisch Instituut, the Royal Netherlands Meteorological Institute is the Dutch national weather forecasting service. Contributes to the calculation of overground water levels by providing data on precipitation and river levels.

- KPN: Dutch landline and mobile telecommunications company. Provides voice and data communication for the parties involved. If the communication fails it becomes very difficult for the parties to perform their tasks.

- Municipality: Administrative division and subdivisions of their respective provinces. Informs the water authorities about developments in the municipality which are important for actions of the water boards. Agrees, where applicable, with the water board and regional services of Rijkswaterstaat on crisis management.

- National crisis coordination centers and General Directorates: Part of the ministries, central nodes in the web of national information, monitor the overall crisis management process, advise responsible ministers, and other national bodies.

- Province: Administrative layer between the national government and the local municipalities, having the responsibility for matters of regional importance. Oversees the water authorities with a view of the safety of the dams. Receives rural water picture and information on tides.

- Rijkswaterstaat: Part of the Dutch Ministry of Infrastructure and the Environment $(\mathrm{VeN})$, and responsible for the design, construction, management and maintenance of the main transport infrastructure facilities in the Netherlands, including the main road and waterway networks, as well as the main water systems.

- Safety region: Organization coordinating disaster management. In a crisis, affected municipalities form a safety region which then coordinates emergency response services (fire brigades, hospitals, and police forces). 
Receives information on tides from Rijkswaterstaat and liaises on interpretation of water image. Liaises with regional water board and with Rijkswaterstaat about the crisis.

Figure 4 presents a use case diagram showing stakeholders and their joint as well as interdependent activities during the crisis.

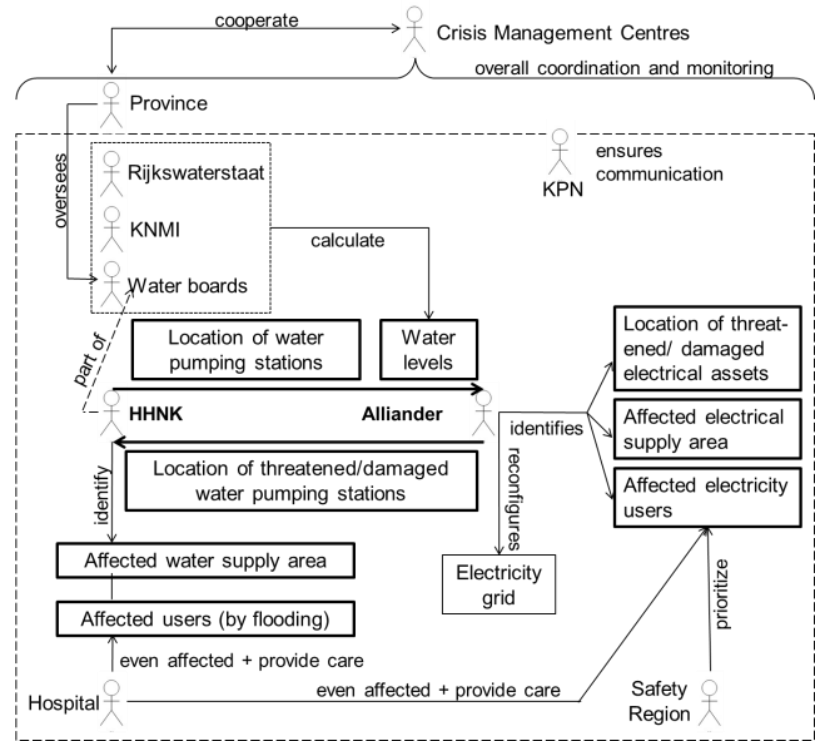

Stakeholder, $\square$ Domain concept, $\rightarrow$ Interaction, Bold: Activities and Domain concepts related to the primary stakeholders

Figure 4. Stakeholders and their roles within crisis management

\section{LINKED DATA}

Linked Data is a way to publish and share data on the Web (Eckartz \& Folmer, 2014). Each data element becomes a resource on the Web with named links to other data elements and properties. The basic element of this structure is a triple consisting two data resources, subject and object, whose relation is specified by a predicate. For example, the DBpedia project transforms information from Wikipedia into Linked Data and publishes it on the web (Lehman et al., 2015). Structured information from the Wikipedia "infoboxes" containing data on geo-coordinates, dates, categorizations, etc. is extracted and put in a uniform dataset which can be queried. Thus, a data point with the ID "The Hague" (subject) can be linked to the concept "City" (object 1) via "isTypeOfHabitat" (predicate 1) as well as to the geo-coordinates $52^{\circ} 5 \mathrm{~N}, 4^{\circ} 19^{\prime} \mathrm{E}$ (object 2) via "hasGeocoordinates" (predicate 2). Consequently, we can retrieve the location of the city The Hague.

In order to describe the semantics of the data, links are provided to vocabularies (also called ontologies or conceptual models). These are models formalizing common conceptualizations for a specific domain, e.g. within the electricity domain concepts such as voltage or transformer are described within an electricity ontology. Data about IDs and the actual voltage level of different transformers can be linked to these concepts, so that it gets clear which transformer has which voltage level.

By publishing data as Linked Data and annotating it with wellknown vocabularies, it becomes much easier for others to understand and use the data. In principle it is possible to annotate the same data with different vocabularies, thus making it possible to 'view' the data from different 'perspectives'.

\section{CONCEPTUAL MODEL FOR INFORMATION EXCHANGE}

Domain concepts are data categories that are relevant for information exchange in a specific scenario. Stakeholders exchange data from these domains and derive new knowledge since semantics of the data are defined through relationships between the domain concepts. Table 5 describes the domain concepts relevant for the current crisis scenario.

\begin{tabular}{|c|c|}
\hline Concept & Description \\
\hline Water Level & $\begin{array}{l}\text { Overground water height measures which } \\
\text { result from a combination of various factors, } \\
\text { such as precipitation, dike breakages, } \\
\text { meltwater of rivers, decreased absorption } \\
\text { ability of the soil, etc. }\end{array}$ \\
\hline $\begin{array}{l}\text { Electricity } \\
\text { Component }\end{array}$ & $\begin{array}{l}\text { All components of the electricity grid, such as } \\
\text { cables, power stations, transformers, etc. } \\
\text { Managed by Alliander. }\end{array}$ \\
\hline Electrical Asset & $\begin{array}{l}\text { Devices responsible for power generation and } \\
\text { transduction to suitable voltage levels. These } \\
\text { include power stations, sub-stations, } \\
\text { transformers, etc. } \\
\text { Sub-class of "Electricity Component". }\end{array}$ \\
\hline Cable & $\begin{array}{l}\text { Devices responsible for power transmission } \\
\text { to the "User". Sub-class of "Electricity } \\
\text { Component". }\end{array}$ \\
\hline $\begin{array}{l}\text { Electrical } \\
\text { Supply Area }\end{array}$ & $\begin{array}{l}\text { Geographical area of responsibility of an } \\
\text { "Electrical Asset". All "Users" in this area } \\
\text { receive electricity from this "Electrical } \\
\text { Asset". }\end{array}$ \\
\hline User & $\begin{array}{l}\text { Electricity consuming objects located in the } \\
\text { "Electrical Supply Area" of an "Electrical } \\
\text { Asset". } \\
\text { E.g. "Pumping Stations", hospitals, schools, } \\
\text { private households. }\end{array}$ \\
\hline $\begin{array}{l}\text { Pumping } \\
\text { Station }\end{array}$ & $\begin{array}{l}\text { Drain flooded area in their "Water Supply } \\
\text { Area" in case of a flooding. Sub-class of } \\
\text { "User" and therefore powered electrically. } \\
\text { Break down in case of a power cut. Managed } \\
\text { by HHNK. }\end{array}$ \\
\hline Other User & $\begin{array}{l}\text { Sub-class of "User" and include all electricity } \\
\text { consuming objects that are NOT "Pumping } \\
\text { Stations". }\end{array}$ \\
\hline $\begin{array}{l}\text { Water Supply } \\
\text { Area }\end{array}$ & $\begin{array}{l}\text { Geographical area of responsibility of a } \\
\text { "Pumping Station". In case of a flooding, the } \\
\text { "Pumping Station" will attempt to drain this } \\
\text { area. All "Other Users" are located in this } \\
\text { area. }\end{array}$ \\
\hline $\begin{array}{l}\text { Water } \\
\text { Resistance } \\
\text { Threshold }\end{array}$ & $\begin{array}{l}\text { Maximal "Water Level" until which an } \\
\text { "Electricity Component" or an "Electrical } \\
\text { Flood Protective Asset" still functions. Each } \\
\text { "Electricity Component" and "Electrical } \\
\text { Flood Protective Asset" is assigned an } \\
\text { individual "Water Resistance Threshold", } \\
\text { respectively. }\end{array}$ \\
\hline
\end{tabular}

Table 5. Domain concepts

By defining relationships between the domain concepts an ontology was developed which provides a triple structure for data linkages (Fig. 6). The ontology also specifies how concepts are encoded, i.e. which type of variable they support when data points are mapped onto the concepts. For example, the concept "ElectricalSupplyArea" is defined by a start- and an end 
postcode. Since Dutch postcodes contain digits and letters the concept will be encoded as a string type variable. By contrast, "WaterLevel" is expressed with a float variable, because it describes the height of water in meters above ground.

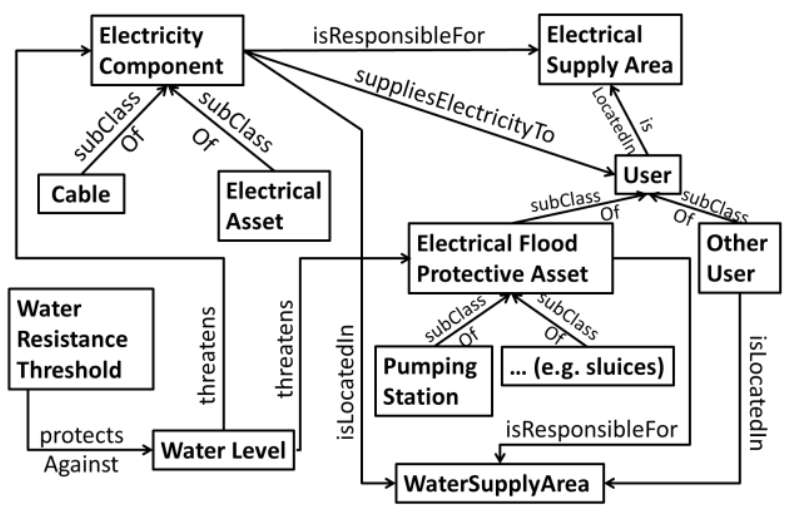

Figure 6. Crisis management ontology

\section{ASSESSMENT OF DATA SHARING SOLUTION}

This section analyzes the level of interoperability of the current data sharing solution. Based on the scope of the data sharing scenario (see Section 3.1 Table 2), measurable concepts were formulated which are summarized in Table 7 (adapted from Folmer, 2012). They are assessed from a generic perspective addressing the general advantages and disadvantages of Linked Data, and a specific perspective analyzing the developed crisis management ontology.

\begin{tabular}{ll}
\hline Scope & Measurable concept \\
\hline Functionality & $\begin{array}{l}\text { Knowledge generation } \\
\text { purpose }\end{array}$ \\
$\begin{array}{l}\text { Capability of the data sharing solution to } \\
\text { provide novel insights. }\end{array}$
\end{tabular}

\section{Dynamic content}

Capability of the data sharing solution to deal with often changing content.

\section{Completeness}

Extend to which the conceptual model is of sufficient breath, depth and scope for the task at hand.

\section{Precision}

Match between actual representation of functions and information vs. required ones in the conceptual model.

$\begin{array}{ll}\text { Durability } & \text { Flexibility } \\ \text { purpose } & \begin{array}{l}\text { Possibility to extend the capabilities of the } \\ \text { datasharing solution for other usage } \\ \text { environments. }\end{array}\end{array}$

\section{External compliance}

Capability of the data sharing solution to adhere to other data sharing conventions (e.g. ease of mapping onto other ontologies).

\section{Maturity of technology}

Amount of expertise in the Linked Data domain and of existing conventions of usage.

\begin{tabular}{ll}
\hline $\begin{array}{l}\text { Small user } \\
\text { community }\end{array}$ & $\begin{array}{l}\text { Installed based } \\
\text { Connection of the data sharing to the current } \\
\text { ICT landscape and business processes of the } \\
\text { data sharing parties. }\end{array}$ \\
\hline Closed & Privacy \\
application & $\begin{array}{l}\text { Extent to which data are protected from open } \\
\text { environment }\end{array}$ \\
\hline access. \\
purpomical & Economic benefit \\
& $\begin{array}{l}\text { Extend to which data sharing solution provides } \\
\text { financial and economic advantages. }\end{array}$ \\
\hline
\end{tabular}

Table 7. Scope of data sharing scenario

The data sharing solution will be rated on a five-point scale for each concept.

1 Concept is very poorly supported by the data sharing solution.

$2[\ldots]$ poorly supported $[\ldots]$

$3[\ldots]$ averagely supported $[\ldots]$

$4[\ldots]$ well supported $[\ldots]$

$5[\ldots]$ very well supported $[\ldots]$

Since the rating is based on the subjective conception of the researchers alone a bias cannot be ruled out. Future research should therefore use more robust and quantitative measures, for example by letting stakeholders rate, too.

\section{Knowledge generation}

Linked Data allows for automated reasoning, since data links are machine-readable and semantics are encoded in these links (Nederstigt et al., 2014). Thus, knowledge that is encoded implicitly within the data links can be extracted. This facilitates decision making since human information processing capabilities are limited and cannot foresee hidden regularities in the datalinks (Endres et al., 2015; Chan and Franklin, 2011).

This advantage is also present in the current crisis management ontology. Electrical Assets that will be at risk for break down in the future can be localized based on their resistance thresholds and predicted water levels.

Rating: 5

\section{Dynamic content}

Linked Data is well suitable for dynamic data due to the decentralized publication model (Tummarello et al., 2007). Data can be locally updated by the responsible stakeholder rather than within a centrally controlled database merge as it is often the case with relational models. Thus, HHNK could upload their real-time data on water levels which are important to determine threatened assets.

Rating: 5

\section{Flexibility}

The triple structure that underlies Linked Data is very flexible. Anyone can always add new facts, i.e., properties to resources (Eckartz \& Folmer, 2014). Ontologies can also be easily extend by either specifying new concepts and relationships or by mapping two different ontologies onto each other.

The crisis management ontology can also be easily adapted to new tasks. For example, other grid managers and operators, such as TenneT, who deals with high voltage components, can share data by adding their domain specific concepts to the ontology.

This reduces re-use barriers because the use of information from additional data sources does not necessitate changes in the application code (Tummarello et al., 2007).

Rating: 5 


\section{External compliance}

Conceptual models that underlie data sharing within Linked Data can easily be mapped onto each other, even if they originate from different domains (Eckartz \& Folmer, 2014). Due to the coherent structure that Linked Data provides for data, all data sharing solutions that support this technology comply well with each other.

However, non-Linked Data sharing solutions that do not have a conceptual model cannot be related to the Linked Data solution because no inter-model mappings can be realized (Tummarello et al., 2007). In these cases external compliance can only be assured by building a conceptual model from scratch for the non-Linked Data solution and map it onto the Linked Data ontology, i.e. transforming data into Linked Data. A very tedious process.

The crisis management ontology complies very well to external ontologies. For example, it uses similar concepts as the IEC CIM ontology (IEC Common Information Model), a widely accepted standard in the utility domain (Simmins, 2011). Due to this overlap in concepts mapping these two ontologies onto each other becomes easier.

Rating: 4

\section{Maturity of technology}

Many mature tools, programs, and libraries are available to interact and operate with Linked Data (Alhajj \& Rokne, 2014). There are various established best practices for publishing and providing Linked Data on the web, mostly published by the W3C (W3C, 2015).

However, it is easy to become overwhelmed by the vast amount of options and novices easily lose the overview (Eckartz \& Folmer, 2014). The same accounts for the great amount of available ontologies. There is neither an official register nor recommendations when to use which one. With respect to this study a new crisis management ontology would not have been created if it had been known that such an ontology already exists.

Moreover, the amount of expertise regarding Linked Data, although quickly growing, is still relatively small, since it is a relatively young technology. Thus, the creation and use of Linked Data are cumbersome and time consuming.

\section{Rating: 3}

\section{Installed Base}

The majority of today's data sharing systems are based on relational data models and do not support Linked Data (Tummarello et al., 2007). They have to be replaced and/or adjusted which is resource consuming since users also have to adapt to this new technology. So it is still doubtful whether there is enough incentive for this change on a national scale in the Netherlands. Nevertheless, Linked Data is only beneficial if it is the dominant solution in a certain context or domain (Tummarello et al., 2007).

The present crisis management ontology is well suited for data exchange between Alliander and HHNK. However, if more stakeholders join in, this solution will be quickly dropped if it is only compatible with a minority of present data management systems.

Rating: 1

\section{Privacy and Security}

In order to make full use of the benefits of Linked Data, data has to be published on the web (Berners-Lee, Hendler \& Lassila, 2001).
Since data is no longer exchanged but interlinked open SPARQL $^{5}$ endpoints allow anyone to access the data (Kalcheva, 2015). Currently, these endpoints do not have any security or access policies in place. A web-service built on top of the data, working like an API, might solve this problem. However, its set-up and maintenance can be costly and time consuming.

The present crisis management ontology contains sensitive data about electricity consumption of private households, location of cables and transformers. It has to be protected to ensure privacy, prevent copper theft and hamper tapping substations for private use (Book, Bastiaans \& Bruinenberg, 2014).

Rating: 2

\section{Economic benefit}

As described in "Installed Base" adapting a company's data architecture to be Linked Data-compatible can be very costly. However, in the long run as benefits of flexibility, automated reasoning and dynamic content strive, significant operating cost savings will become prevalent (Steinfield et al., 2011).

Rating: 3

\section{Completeness}

Linked Data allows the data sharing parties to constantly adjust the definitions and interrelations in a decentralized manner (Tummarello et al., 2007). This allows them to easily improve the level to which all necessary information elements are covered. Too many or missing information elements will have a negative impact on interoperability (Folmer, 2012). Thus, redundancy in information exchange is reduced. Traditional standards foresee exchanging messages when the relevant event has occurred, e.g. after delivery, an invoice is sent. However, Linked Data rather references information by keeping it at its source and linking it when queries for information are received (Kalcheva, 2015).

The covered functions of Linked Data can be extended by adjusting SPARQL queries. In principle, any question can be asked to the data. This acknowledges the unpredictability within a crisis as the user can simply alter his query depending on situational changes.

Rating: 5

\section{Precision}

The more accurate data concepts are defined the more powerful Linked Data is since automated reasoning is not hampered by ambiguous concept names. For example, "WaterLevel" might either refer to the overground water height or to the groundwater level. This distinction is very important in the crisis management ontology because only the former concept is needed for the tasks at hand. Since this ontology was developed in cooperation with the stakeholders it was ensured that definitions were sufficiently precise for them. However, if more stakeholders adopt this data sharing solution the level of precision might not be sufficient any more.

One of the main drawbacks in this respect is the limited expressiveness of Linked Data. Different concepts can be the same within a certain context but different within another (Kalcheva, 2015). For example, in the staffing industry workers are seen as resources in the same way as Electrical Assets are considered to be resources in the utility domain. Therefore the triples "Workers" "sameAs" "Resources"and "ElectricalAssets" "sameAs" "Resources" are semanticall true in the context of the staffing industry and the utility domain respectively. However the concepts "Workers" and "ElectricalAssets" certainly do not refer to the same concept outside these contexts.

\footnotetext{
${ }^{5}$ Query language for Linked Data.
} 
This requires an additional specification of the concepts and a precise definition of the contexts in which different concepts are the same (Hammer \& McLeod, 1981). This might be problematic for data sharing within crisis management as crises situations often change unpredictably and therefore give rise to a vast number of context constellations.

Rating: 4

\section{DISCUSSION AND FUTURE WORK}

The aim of this study was to create a data sharing solution for crisis management in order to examine whether Linked Data improves interoperability between the data sharing parties. Results revealed that Linked Data in general and the crisis management ontology in particular provide a very good method to improve interoperability providing that Linked Data will be used more widely.

In order to further test the suitability of this Linked Data-based information exchange, future work should focus on the development of an implementation in order to test data sharing in practice. For example, a graphical, map-based web application could show the real-time development of water levels in combination with the location of Electrical Assets and of Pumping Stations. Based on the underlying crisis management ontology the application could visualize the assets that are at risk, damaged or have broken down. By showing their respective supply area affected users can be localized.

Moreover, further insights might be gained by extending this data sharing solution to other aspects of crisis management, such as domino effects (van Dongen et al., 2013), gridreconfiguration (Aarsen et al., 2015), and emergency response processes (Fan \& Zlatanova, 2010).

First, in the Western world vital processes of societal life are highly interdependent. For instance, industry depends on electricity for the production of goods and on a functioning transport system (Fig 8)

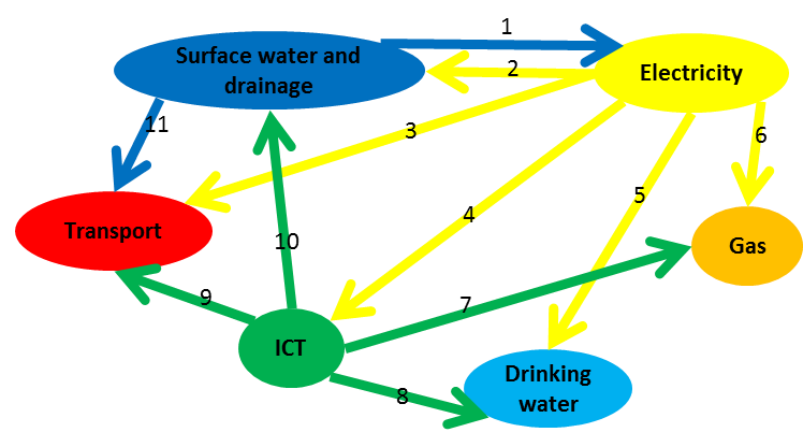

1 Prevent exposure of water; 2 Provide current for purification of the ground; 3 Provide current for traffic flow, bridges, tunnels, trains, crossings, petrol stations; 4 Provide current for telecommunication, internet, etc.; 5 Provide current for Electrical Assets and water extraction; 6 Provide current for operating systems; 7 Provide operating systems for gas processing; 8 Provide operating systems for water preparation; 9 Provide operating for transport management; 10 Provide operating systems for ground control, sewage treatment, drainage, and purification; 11 Prevent exposure of water

Figure 8. Key dependencies between sectors (adapted from van Dongen et al., 2013)

How is this complex system affected by a crisis? Which vital sectors are threatened at what point in time and which consequences does this have for humans? Since the electricity and the water management sectors are important factors in society, the current crisis management scenario is well suitable to explore domino-effects during a flood-caused power cut.
Linked Data could help to interrelate consequences within and between specific sectors in order to predict the course of the domino effect. By mapping the data onto a time ontology, accuracy of this prediction and ecological validity of the model might improve (Fig. 9).

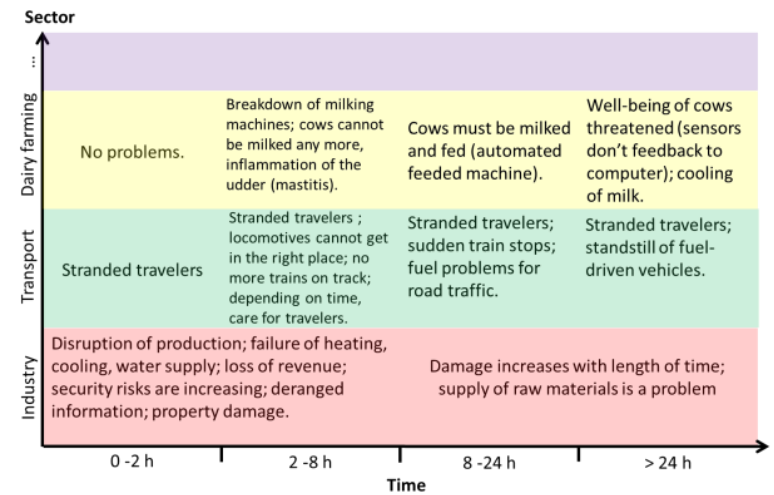

Figure 9. Temporal effect-chain of social disruption after a power cut (adapted from Book, Bastiaans \& Bruinenberg, 2014)

Second, an important process in the current crisis management scenario is the reconfiguration of the electrical grid after the breakdown of an Electrical Asset. In order to re-ensure electricity supply in the affected area Alliander has to check which additional power generating sources are eligible for this purpose. Solar panels on private roofs represent such a source (Aarsen et al., 2015). They are highly distributed across the country, meaning that it is quite likely that some panels are always in the vicinity of an affected supply area. Moreover, their network represents a very robust source of power generation: if one panel fails others can make up for the individual breakdown. Gathering data on location and production rate of solar panels and linking them to the data sets described in this use case could provide a rich source for improving grid reconfiguration during a crisis.

Although no fixed infrastructure is in place yet to connect solar panels to affected users, a mobile system could be flexibly set up. Emergency aggregates could be transported to nearby solar panel sites to be charged there rather than taking them back to the distant headquarter of the grid operator. In the same way electrically powered emergency vehicles such as fire brigade and police cars could be re-charged in this way.

Third, suggestions so far have mainly focused on increasing the amount of interlinked domain-specific data, i.e. information about domains that are affected by a crisis. The aim clearly was to retrieve more information from these interdependencies, leaving out questions such as when and how this specific information will be of use in the whole emergency response process.

By modeling emergency response processes such as firefighting, tasks for all actors are well specified (Fig. 10). In a follow-up project these process models could be linked to the crisis management ontology. In this way actors know exactly when and where to request certain information from.

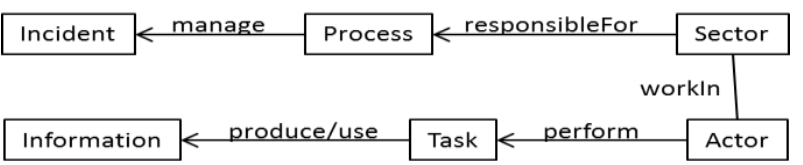

Figure 10: Conceptual model of general emergency response (adapted from Zlatanova, 2010) 
In conclusion, the present study provided evidence for improved interoperability if information is preparing and shared within a common Linked Data-based conceptual framework. Crisis managers will be able to accurately assess the situation and make fast and adequate decisions in order to optimize crisis management. Follow-up project should adopt Linked Data to explore other aspects of crisis management in order to improve ecological validity of research in this domain.

\section{REFERENCES}

Aarsen, R., Ramkisoen, M., Janssen, M., Quak, W. \& Verbree, E., 2015. Installed Base Registration of Decentralized Solar Panels. Submitted to Gi4DM workshop at ISPRS GEOSPATIAL WEEK 2015.

ACIR, 2005. De vrijblijvendheid voorbij. Retrieved from: http://www.infopuntveiligheid.nl/Publicatie/DossierItem/68/778 /acir-rapport-commissie-hermans-de-vrijblijvendheidvoorbij.html on 28th April 2015.

Alhajj, R. \& Rokne, J., 2014. Encyclopedia of Social Network Analysis and Mining, Springer Science Business Media, New York, pp. 811-813.

Berners-Lee, T., Hendler, J. \& Lassila, O., 2001. The semantic web - A new form of Web content that is meaningful to computers will unleash a revolution of new possibilities. Scientific American 284, pp. 34-43.

Book, M. Bastiaans, S. \& Bruinenberg, J., 2014. Crisis management discussion. Private communication.

CERISE, 2015. CERISE-SG: Alignment of the information infrastructure architecture of utility companies with related architectures: enlarging circles (for smart grids). Retrieved from http://www.cerise-project.nl/index.php?lang=en\&Itemid=103 on 23rd April.

Chan, S.W.K. \& Franklin, J., 2011. A text-based decision support system for financial sequence prediction. Decision Support Systems, 52, pp. 189-198.

de Landmeter, R. \& van Giessel, K., 2015. Crisis management discussion. Private communication.

Eckartz S. \& Folmer, E., 2014. Stappenplan: Best practice voor het publiceren van Linked Data. Retrieved from http://www.pilod.nl/wiki/BoekTNO/stappenplan om 28th April 2015.

Endres, M.J., Houpt, J.W., Donkin C. \& Finn, P., 2015. Working Memory Capacity and Redundant Information Processing Efficiency. Frontiers in Psychology: Quantitative Psychology and Measurement, 6, pp. 1-18.

Esri, 2011. Uitleg over het nieuwe Landelijk Crisismanagement Systeem. Retrieved from http://www.esri.nl/nieuwsmedia/nieuws-gis/uitleg-over-het-nieuwe-landelijkcrisismanagement-systeem on 23rd April 2015.

Fan, Z. \& Zlatanova, S., 2010. Exploring ontology potential in emergency management. Presented at the conference on geomatics for crisis management. Torino, Italy.

Firebrary, 2015. Firebrary Home. Retrieved from http://www.firebrary.com/nl/ on 23rd April, 2015.
Hammer, M. \& McLeod, D., 1981. Database description with SDM: A semantic database model. ACM Transactions on Database Systems, 6(3), pp. 351-386.

Kalcheva, K., 2015. A model to showcase the potential for LD application within (financial) business processes. In press.

Lehmann, J., Isele, R., Jakob, M., Jentzsch, A., Kontokostas, D., Mendes, P.N., Hellmann, S., Morsey, M., van Kleef, P., Auer, S. \& Bizer, C., 2015. Dbpedia - A Large-scale, Multilingual Knowledge Base Extracted from Wikipedia. Semantic Web Journal, 6(2), pp. 167-195.

Nederstigt, L.J., Aanen, S.S., Vandic, D., \& Frasincar, F., 2014. FLOPPIES: A Framework for Large-Scale Ontology Population of Product Information from Tabular Data in E-commerce Stores. Decision Support Systems. 59, pp. 296-311.

Simmins, J.J., 2011. The impact of PAP 8 on the Common Information Model (CIM). Power Systems Conference and Exposition (PSCE), IEEE/PES, Phoenix, AZ.

Steinfield, C.W., Markus, M.L., \& Wigand, R.T., 2011. Cooperative Advantage and Vertical Information System Standards: An Automotive Supply Chain Case Study. (IEEE), pp. 1-10.

Tummarello, G., Delbru, R., \& Oren, E., 2007. Sindice.com: Weaving the Open Linked Data. ISWC07ASWC07 Proc. 6th Int. Semantic Web 2nd Asian Conf. Asian Semantic Web Conf. pp. 552-565.

van Dongen, K., Stolk, D., Weber, L. \& de Lange, M., 2013. Informatiepreparatie overstromingsrisico's en domino-effecten: Een verkenning. Retrieved from http://www.infopuntveiligheid.nl/Publicatie/DossierItem/10/548 8/informatiepreparatie-overstromingsrisicos-en-dominoeffecten-een-verkenning.html on 28th April 2015.

van Leeuwen, B., 2015. Realtime Linked Open Data Brandweer Amsterdam-Amstelland, PiLOD Conference, Utrecht, Netherlands. Retrieved from http://www.pilod.nl/w/images/2/29/20150402_Waternet_Bart_v an_Leeuwen.pdf on 28th April 2015.

Waterschappen, 2015. Ontdek ons. Retrieved from http://www.waterschappen.nl/ontdek-ons/ on 28th April.

World Wide We Consortium (W3C), 2015. Linked Data. Retrieved from http://www.w3.org/standards/semanticweb/data on 24th April 2015.

Zlatanova, S. 2010. Formal modelling of processes and tasks to support use and search of geo-information in emergency response. $13^{\text {th }}$ Annual International Conference and Exhibition on geospatial Information Technology and Applications, Gurgaon, India, pp. 1-10.

Zlatanova, S. Ghawana, T., Kaur, A. \& Neuvel, J., 2014. Integrated Flood Disaster Management and Spatial Information: Case Studies of Netherlands and India. The International Archives of the Photogrammetry, Remote Sensing and Spatial Information Sciences, Volume XL-8, pp. 147-154. 